\title{
STUDI KUALITAS MIKROBIOLOGI AIR SUMUR GALI SEBELUM DAN SESUDAH MENGGUNAKAN CHLORINE DIFFUSER DI DESA SELABAYA KECAMATAN KALIMANAH KABUPATEN PURBALINGGA TAHUN 2018
}

\author{
Inayatus sholikhah ${ }^{1)}$, Yulianto ${ }^{2)}$ \\ Jurusan Kesehatan Lingkungan, Politeknik Kesehatan Kemenkes Semarang, \\ Jl.Raya Baturaden KM 12 Purwokerto, Indonesia
}

\begin{abstract}
Abstrak
Air sumur gali yang berasal dari air tanah seringkali menimbulkan permasalahan. Permasalahan yang timbul yakni sering dijumpai bahwa kualitas air tanah yang digunakan oleh masyarakat kurang memenuhi syarat bahkan di beberapa tempat tidak layak untuk dikonsumsi. Sebagai contoh air tanah yang berbau, berasa, berwarna, keruh, mengandung zat besi (Fe) dan Coliform (BPPT,2010). Tujuan dari penelitian ini adalah untuk mengetahui jumlah Coliform pada air sumur gali, dan mengetahui kondisi sanitasi sumur gali. Jenis penelitian yang digunakan adalah penelitian deskriptif yang bertujuan untuk mengetahui terjadi perubahan atau tidak pada air sumur gali setelah pemasangan chlorine diffuser di Desa Selabaya Kecamatan Kalimanah Kabupaten Purbalingga tahun 2018. Hasil Penelitian menunjukan bahwa jumlah Coliform dalam air sumur gali masih ada yang tidak sesuai dengan standar yang berlaku, setelah dipasang chlorine diffuser ada 3 sumur gali yang tetap, dan ada 5 sumur gali yang kualitas airnya menjadi lebih baik. Kesimpulan bahwa Kualitas mikrobiologi di Desa Selabaya Kecamatan Kalimanah Kabupaten Purbalingga didapatkan hasil setelah pemasangan chlorine diffuser kualitas airnya ada yang menjadi lebih baik dan ada yang tetap disarankan pada masyarakat agar dapat menggunkan chlorine diffuser untuk mendesinfeksi air sumur gali.
\end{abstract}

Kata kunci: Coliform; Sumur Gali

\begin{abstract}
Quality study of water treatment microbiology before and after using chlorine diffuser in Villages Selabaya District Kalimanah District Purbalingga In 2018. Well water dug from ground water often causes problems. Problems arise that is often found that the quality of groundwater used by the community is less qualified even in some places not worth to be consumed. For example ground water that smells, tastes, colored, turbid, contains iron (Fe) and Coliform (BPPT, 2010). The purpose of this research is to know the number of Coliform in digging well water, and to know the condition of sanitation of dug wells. The type of research used is descriptive research that aims to determine whether or not changes in dug well water after installation of chlorine diffuser in Selabaya Village Kalimanah District Purbalingga District in 2018. The results showed that the number of Coliform in dug well water still exist which is not in accordance with the applicable standards, after installed chlorine diffuser there are $3 \mathrm{dug}$ wells are fixed, and there are 5 wells dug the water quality to be better. The results showed that the number of Coliform in dug well water still exist which is not in accordance with the applicable standards, after installed chlorine diffuser there are 3 dug wells are fixed, and there are 5 wells dug the water quality to be better. The conclusion that the quality of microbiology in Selabaya Village, Kalimanah District, Purbalingga Regency is obtained after the installation of chlorine diffuser water quality there is a better and there are still recommended to the community in order to use chlorine diffuser to disinfect well water dig.
\end{abstract}

Keywords: Coliform; Dug Well

\footnotetext{
${ }^{1)}$ E-mail: inaynay31@yahoo.co.id

${ }^{2)}$ E-mail: yulianto_61@yahoo.com
} 


\section{Pendahuluan}

Berdasarkan ketentuan dalam Peraturan Pemerintah Nomor 66 Tahun 2014 tentang Kesehatan Lingkungan, kualitas lingkungan yang sehat ditentukan melalui pencapaian atau pemenuhan Standar Baku Mutu Kesehatan Lingkungan dan Persyaratan Kesehatan. Air merupakan salah satu media lingkungan yang harus ditetapkan Standar Baku Mutu Kesehatan Lingkungan dan Persyaratan Kesehatan.

Standar Baku Mutu Kesehatan Lingkungan untuk media Air untuk Keperluan Higiene Sanitasi meliputi parameter fisik, biologi, dan kimia yang dapat berupa parameter wajib dan parameter tambahan. Parameter wajib merupakan parameter yang harus diperiksa secara berkala sesuai dengan ketentuan peraturan perundang-undangan, sedangkan parameter tambahan hanya diwajibkan untuk diperiksa jika kondisi geohidrologi mengindikasikan adanya potensi pencemaran berkaitan dengan parameter tambahan (Peraturan Menteri Kesehatan Republik Indonesia No.32 tahun 2017 tentang Standar Baku Mutu Kesehatan Lingkungan dan Persyaratan Kesehatan Air Untuk Keperluan Higiene Sanitasi, Kolam Renang, Solus Per Aqua, dan Pemandian Umum).

Sumur gali adalah salah satu sumber air bersih yang sering digunakan oleh sebagian besar masyarakat Indonesia. Air sumur gali yang berasal dari air tanah seringkali menimbulkan permasalahan. Permasalahan yang timbul yakni sering dijumpai bahwa kualitas air tanah yang digunakan oleh masyarakat kurang memenuhi syarat bahkan di beberapa tempat tidak layak untuk dikonsumsi. Sebagai contoh air tanah yang berbau, berasa, berwarna, keruh, mengandung zat besi (Fe) dan Coliform (BPPT,2010). Air sumur gali yang berasal dari lapisan tanah relatif dekat dari permukaan tanah, oleh karena itu dengan mudah terkena kontaminasi melalui rembesan. Umumnya rembesan berasal dari tempat buangan kotoran manusia kakus/jamban dan hewan, juga dari limbah sumur itu sendiri, baik karena lantainya maupun saluran air limbahnya yang tidak kedap air. Keadaan konstruksi dan cara pengambilan air sumur pun dapat merupakan sumber kontaminasi, misalnya sumur dengan konstruksi terbuka dan pengambilan air dengan timba. Kualitas air sumur gali sangat dipengaruhi keadaan sanitasi sumur gali yang kurang baik dengan merembesnya atau masuknya kembali air kotor ke dalam sumur, akhirnya mencemari air sumur yang digunakan untuk kebutuhan sehari-hari.
Berdasarkan pemeriksaan bakteriologis pada berbagai macam sumber air di Desa Selabaya yang dilakukan di UPTD Laboratorium Kesehatan Kabupaten Purbalingga di dapatkan hasil 8 sumber mata air dengan hasil pemeriksaan bakteriologis yang berkisar antara 93 - >2400 MPN/100 ml.

Persyaratan parameter biologi dalam standar baku mutu kesehatan lingkungan untuk media air untuk keperluan higiene sanitasi menurut "Peraturan Menteri Kesehatan RI No 32 Tahun 2017 tentang standar baku mutu kesehatan lingkungan dan persyaratan kesehatan air untuk keperluan higiene sanitasi, kolam renang, solus per aqua, dan pemandian umum" adalah apabila Coliform standar baku mutunya dibawah 50 CFU / 100ml dan E. coli standar baku mutunya $0 \mathrm{CFU} / 100 \mathrm{ml}$. Eschericia coli merupakan kelompok bakteri coliform. Semakin tinggi kontaminasi E. coli di air dapat mengakibatkan gangguan pencernaan sampai diare. Kondisi air yang tercemar oleh E. coli dapat dilakukan pengolahan air untuk menurunkan kadarnya.

Berdasarkan latar belakang diatas penulis tertarik untuk mengadakan penelitian dengan judul "Studi Kualitas Mikrobiologi Air Sumur Gali Sebelum dan sesudah menggunakan Chlorine Diffuser di Desa Selabaya Kecamatan Kalimanah Kabupaten Purbalingga Tahun 2018”.

\section{Bahan dan Metode}

Subjek penelitian adalah air sumur gali yang digunakan masyarakat di Desa Selabaya Kecamatan Kalimanah Kabupaten Purbalingga, jumlahnya sebanyak 8 sampel.

Jenis penelitian yang digunakan adalah deskriptif, penelitian dilakukan dengan pengumpulan data lapangan dan laboratorium yang kemudian dianalisis dan dibandingkan dengan persyaratan yang berlaku.

Waktu dalam penelitian ini dibagi menjadi 3 tahap yang pertama tahap persiapan September 2017 - Januari 2018, tahap pelaksanaan Januari - Febuari 2018, dan tahap penyelesaian Maret - Mei 2018.

Cara pengumpulan data yaitu dengan cara Observasi dilakukan dengan cara pengamatan langsung di lokasi penelitian yaitu di sumur gali Desa Selabaya Kecamatan Kalimanah Kabupaten Purbalingga, dan Pengukuran laboratorium dilakukan terhadap subjek yaitu coliform pada sumber mata air. 


\section{Hasil dan Pembahasan}

A. Data umum

Keadaan geografis : Desa Selabaya Kecamatan Kalimanah Kabupaten Purbalingga merupakan desa yang memiliki luas wilayah secara keseluruhan 109.65 ha. Secara geografis wilayah Desa Selabaya memiliki batas-batas wilayah sebagai berikut : di sebelah utara ada Desa Babakan dan Desa Kalikabong, Timur ada Desa Karang Petir dan Desa Grecol, Selatan ada Desa Kalimanah Wetan dan Kalimanah Kulon, Barat ada Desa Karangsari dan Desa Klapasawit.

Keadaan demografi : Jumlah penduduk di desa selabaya adalah 3852 jiwa, dengan komposisi penduduk laki laki 1946 jiwa / 50,52\% dan komposisi penduduk perempuan 1906 jiwa, jumlah KK di desa selabaya 1208 jiwa / 49,48\% dan jumlah KK miskin 262 jiwa. Desa selabaya terorganisir dalam 2 Wilayah Dusun. 7 Rukun Warga dan 26 Rukun Tetangga.

B. Data Khusus

\begin{tabular}{|c|c|c|c|c|c|c|}
\hline No. & $\begin{array}{c}\text { Respond } \\
\text { en }\end{array}$ & $\mathrm{a}$ & $\mathrm{b}$ & $\mathrm{c}$ & $\mathrm{d}$ & $\mathrm{e}$ \\
\hline 1 & SGL 1 & $\begin{array}{l}\text { Tid } \\
\mathrm{ak}\end{array}$ & $\mathrm{Ya}$ & Tidak & $\mathrm{Ya}$ & $\begin{array}{c}\text { Tid } \\
\text { ak }\end{array}$ \\
\hline 2 & SGL 2 & $\mathrm{Ya}$ & $\begin{array}{l}\text { Tid } \\
\mathrm{ak}\end{array}$ & Tidak & $\mathrm{Ya}$ & $\begin{array}{c}\text { Tid } \\
\text { ak }\end{array}$ \\
\hline 3 & SGL 3 & $\mathrm{Ya}$ & $\begin{array}{c}\text { Tid } \\
\mathrm{ak}\end{array}$ & Tidak & $\mathrm{Ya}$ & $\begin{array}{c}\text { Tid } \\
\text { ak }\end{array}$ \\
\hline 4 & SGL 4 & $\mathrm{Ya}$ & $\mathrm{Ya}$ & Tidak & $\mathrm{Ya}$ & $\begin{array}{c}\text { Tid } \\
\text { ak }\end{array}$ \\
\hline 5 & SGL 5 & $\mathrm{Ya}$ & $\mathrm{Ya}$ & Tidak & $\begin{array}{c}\text { Tid } \\
\text { ak }\end{array}$ & $\begin{array}{c}\text { Tid } \\
\text { ak }\end{array}$ \\
\hline 6 & SGL 6 & $\mathrm{Ya}$ & $\begin{array}{l}\text { Tid } \\
\text { ak }\end{array}$ & Tidak & $\mathrm{Ya}$ & $\begin{array}{c}\text { Tid } \\
\text { ak }\end{array}$ \\
\hline 7 & SGL 7 & $\mathrm{Ya}$ & $\mathrm{Ya}$ & Tidak & $\mathrm{Ya}$ & $\mathrm{Ya}$ \\
\hline \multirow[t]{2}{*}{8} & SGL 8 & $\mathrm{Ya}$ & $\mathrm{Ya}$ & Tidak & $\mathrm{Ya}$ & $\begin{array}{c}\text { Tid } \\
\text { ak }\end{array}$ \\
\hline & $\begin{array}{c}\text { Rata- } \\
\text { rata }\end{array}$ & $\mathrm{Ya}$ & $\mathrm{Ya}$ & Tidak & $\begin{array}{c}\text { Tid } \\
\text { ak }\end{array}$ & $\begin{array}{c}\text { Tid } \\
\text { ak }\end{array}$ \\
\hline
\end{tabular}

1. Tabel 4. 2 Chek list konstruksi sumur Konstruksi sumur gali adalah konstruksi atau keadaan fisik sumur gali yang meliputi dinding, lantai, bibir sumur, saluran pembuangan limbah, dan dilengkapi dengan kerekan timba dengan gulungannya atau pompa (Dep.Kes.RI, 1992). Berdasarkan tabel 4.2 didapatkan hasil penelitian terhadap 8 SGL, konstruksi sumur gali yang memenuhi syarat sebanyak3 (37,5 \%) SGLyang masuk dalam kategori baik dan tidak memenuhi syarat sebanyak $5(62,5 \%)$ SGL dalam kategori tidak baik.

Berdasarkan data dari 8 sumur gali di desa Selabaya yang menjadi objek penelitian, sebagian besar konstruksi sumur gali belum memenuhi syarat, diantaranya :

a. Masih ada 1 sumur yang jamban dan sumber pencemar lain pada jarak kurang dari 11 meter didekat sumur. Jarak sumur gali dengan sumber pencemar seperti jamban keluarga dapat berpengaruh terhadap kandungan bakteri coliform pada air sumur gali. Menurut Depkes RI (Panut Setiyanto. 2004, h.27) dinyatakan bahwa, apabila letak sumber pencemar lebih tinggi dari sumur gali dan diperkirakan aliran air tanah mengalir ke sumur gali maka jarak minimal sumur gali terhadap sumber pencemar adalah $11 \mathrm{~m}$, dan apabila letak sumber pencemar sama atau lebih rendah dengan sumur gali maka jarak minimalnya adalah $9 \mathrm{~m}$, dengan jarak tersebut diharapkan pergerakan bakteri coliform tidak dapat menembus kedalam sumur gali. Sebaiknya hindarkan atau jauhkan kandang ternak dan sumber pencemar lainnya dari sumur, untuk mengurangi risiko pencemaran terhadap kualitas air secara bakteriologis. Semakin dekat jarak pencemar dengan sumur gali maka risiko tingkat pencemaran semakin tinggi.

b. Masih ada 3 sumur yang lantainya belum kedap air, karena bila tidak kedap air bisa terjadi kebocoran atau rembesan dari sumber pencemar.

c. Semua tinggi bibir sumur masih belum ada yang memenuhi syarat.

d. Dinding sumur dalamnya minimal 3 meter dari lantai, sehingga air tidak dapat merembes kedalam sumur, tumbuhnya lumut di dinding sumur akan menjadikan keadaan lembab. Hal ini akan berpengaruh terhadap bakteriologis, karena bakteri akan tumbuh di tempat yang lembab, dari 8 sumur masih ada 1 sumur yang belum memenuhi syarat.

e. Sumur yang tidak diberi penutup akan mempunyai kemungkinan untuk tercemar, sebaiknya jika sumur digunakan maka lebih baik diberi penutup untuk meminimalisir terjadinya pencemaran. 
2. Tabel 4.8 pengukuran tinggi air, diameter dan volume air sumur gali

\begin{tabular}{cccccccc}
\hline $\begin{array}{l}\mathrm{N} \\
\mathrm{o}\end{array}$ & Sampel & $\begin{array}{c}\mathrm{T} 1 \\
(\mathrm{~m})\end{array}$ & $\begin{array}{c}\mathrm{T} 2 \\
(\mathrm{~m})\end{array}$ & $\begin{array}{c}\mathrm{T} 3 \\
(\mathrm{~m})\end{array}$ & $\begin{array}{c}\mathrm{T} 4 \\
(\mathrm{~m})\end{array}$ & $\begin{array}{c}\mathrm{D} \\
(\mathrm{m})\end{array}$ & $\begin{array}{c}\text { V.air } \\
\left(\mathrm{m}^{3}\right)\end{array}$ \\
\hline 1 & SGL 1 & 0,73 & 2,24 & 6 & 4,48 & 0,8 & 2,25 \\
2 & SGL 2 & 0,5 & 3,84 & 7 & 3,66 & 0,89 & 2,55 \\
3 & SGL 3 & 0,37 & 1,62 & 3,5 & 2,25 & 0,76 & 1,93 \\
4 & SGL 4 & 0,78 & 2,65 & 5 & 3,13 & 0,79 & 1,94 \\
5 & SGL 5 & 0,31 & 1,16 & 2 & 1,15 & 0,8 & 0,72 \\
6 & SGL 6 & 0,53 & 1,27 & 5 & 4,26 & 0,89 & 2,98 \\
7 & SGL 7 & 0,72 & 3,70 & 6 & 3,02 & 0,8 & 1,89 \\
8 & SGL 8 & 0,72 & 2,91 & 4 & 1,81 & 0,74 & 1,05 \\
\hline
\end{tabular}

Perhitungan volume air sumur:

$\mathrm{V}=(1 / 4 \mathrm{x} \pi \mathrm{x} \mathrm{d} 2) \times \mathrm{T} 4$

Hasil pengukuran volume air sumur gali terbanyak di SGL 6 dengan volume 2,98 $\mathrm{m}^{3}$ dan volume air paling sedikit di SGL 5 dengan volume $0,72 \mathrm{~m}^{3}$.

Hasil pengukuran volume air sumur gali terbanyak di SGL 6 dengan volume 2,98 $\mathrm{m}^{3}$ dan volume air paling sedikit di SGL 5 dengan volume $0,72 \mathrm{~m}^{3}$. Volume air di dalam sumur gali berpengaruh terhadap cepat lambatnya proses chlorin diffuser itu habis. Semakin banyak volume air dalam sumur maka semakin cepat chlorine diffuser habis.

3. Proses pembuatan chlorine diffuser

Pengembangan dari Chlorine diffuser tersebut adalah tabung terbuat dari tabung PVC 2 inchi, dengan panjang total $40 \mathrm{~cm}$ dan terisi campuran kaporit $60 \%$ dan pasir dengan perbandingan 1:4 selanjutnya dimasukkan dalam PVC dengan ketebalan 20 $\mathrm{cm}$ (1/2 panjang tabung). Jumlah lubang sebanyak 10 buah (dibagian atas dan bawah masing-masing 5 buah) dengan diameter 5 $\mathrm{mm}$.

a. Cara membuat chlorine diffuser:

1. Siapkan alat dan bahan

2. Pilih pvc yang besarnya 2 in

3. Potong pvc dengan panjang $40 \mathrm{~cm}$

4. Lubangi dop dengan jumlah lubang 10 (dibagian atas dan bawah masing masing 5 buah) dop akan digunakan untuk menutup pipa

5. Buatlah campuran $4 \mathrm{~kg}$ pasir dan $1 \mathrm{~kg}$ kaporit

6. Masukan dakron kedalam pipa pada kedua sisinya

7. Isi dengan campuran kaporit dan pasir yang telah dibuat

8. Tutuplah ujung pipa dengan dop pvc, dop pada bagian bawah di selotip agar lebih kuat
9. Siapkan tali plastik panjang $\leq 2$ meter. Buatlah lubang pada kedua sisi pipa, Selanjutnya masukan ujung tali plastik ke lubang untuk dibuat simpul mati, alat siap digunakan.

b. Cara pemasangan chlorine diffuser:

1. Siapkan tali plastik yang cukup kuat dan panjang disesuaikan dengan kedalaman sumur

2. Potong tali panjangnya sesuai kedalaman sumur

3. Ikat kuat tali ke lubang yang telah disiapkan di chlorine diffuser

4. Turunkan chlorine diffuser kedalam air sumur hingga terendam dalam air sedalam $\leq 1$ meter dari permukaan air

5. Potong ujung tali dan bakar ujung tali agar rapi dan tali tidak rusak

6. Ikatkan tali pada paku didekat sumur atau pada dinding sumur untuk mencegah chlorine diffuser lepas dan tenggelamkan kedalam dasar sumur.

c. Prinsip kerja chlorine diffuser:

1. Pembubuhan kaporit secara perlahan pada sarana air bersih.

2. Terjadinya difusi (pencampuran) kaporit dalam tabung dengan air secara perlahan.

3. Pengaturan kadar chlor yang sesuai kebutuhan.

4. Air akan masuk melalui lubanglubang yang ada di pipa pvc - masuk ke celah pasir- masuk ke lubang kecil - masuk melalui celah pasir dan bercampur dengan kaporit yang larut dengan air - larutan kaporit keluar melalui lubang pipa dan celah celah pasir - ke badan air - bercampur dengan air dan mendesinfeksi air. 
4. Tabel 4. 9 Hasil Pengukuran Sisa Chlor

\begin{tabular}{|c|c|c|c|c|}
\hline No. & Lokasi & $\begin{array}{c}\text { Tanggal / } \\
\text { pukul }\end{array}$ & Hasil & Keterangan \\
\hline 1 & SGL 1 & $\begin{array}{l}12 / 4 / 18 / \\
08.00\end{array}$ & $0,1 \mathrm{mg} / \mathrm{l}$ & $\begin{array}{c}\text { Tidak } \\
\text { memenuhi } \\
\text { syarat }\end{array}$ \\
\hline 2 & SGL 2 & $\begin{array}{l}12 / 4 / 18 / \\
08.15\end{array}$ & $0,4 \mathrm{mg} / \mathrm{l}$ & $\begin{array}{c}\text { Memenuhi } \\
\text { syarat }\end{array}$ \\
\hline 3 & SGL 3 & $\begin{array}{l}12 / 4 / 18 / \\
08.25\end{array}$ & $0,2 \mathrm{mg} / \mathrm{l}$ & $\begin{array}{l}\text { Memenuhi } \\
\text { syarat }\end{array}$ \\
\hline 4 & SGL 4 & $\begin{array}{l}12 / 4 / 18 / \\
08.35\end{array}$ & $0,2 \mathrm{mg} / \mathrm{l}$ & $\begin{array}{l}\text { Memenuhi } \\
\text { syarat }\end{array}$ \\
\hline 5 & SGL 5 & $\begin{array}{l}12 / 4 / 18 / \\
08.50\end{array}$ & $0,3 \mathrm{mg} / \mathrm{l}$ & $\begin{array}{l}\text { Memenuhi } \\
\text { syarat }\end{array}$ \\
\hline 6 & SGL 6 & $\begin{array}{l}12 / 4 / 18 / \\
09.00\end{array}$ & $0,8 \mathrm{mg} / \mathrm{l}$ & $\begin{array}{c}\text { Tidak } \\
\text { Memenuhi } \\
\text { syarat }\end{array}$ \\
\hline 7 & SGL 7 & $\begin{array}{l}12 / 4 / 18 / \\
09.20\end{array}$ & $0,2 \mathrm{mg} / \mathrm{l}$ & $\begin{array}{c}\text { Memenuhi } \\
\text { syarat }\end{array}$ \\
\hline 8 & SGL 8 & $\begin{array}{l}12 / 4 / 18 / \\
09.30\end{array}$ & $0,5 \mathrm{mg} / \mathrm{l}$ & $\begin{array}{l}\text { Memenuhi } \\
\text { syarat }\end{array}$ \\
\hline \multicolumn{3}{|c|}{ Rata rata } & $0,3 \mathrm{mg} / \mathrm{l}$ & \\
\hline
\end{tabular}

Hasil penelitian kualitas air sumur gali desa Selabaya menunjukkan bahwa sebagian besar kadar sisa klor di air sumur gali desa Selabaya memenuhi syarat. Kadar sisa klor yang tidak memenuhi syarat sebesar $25 \%$. Rata - rata kadar sisa klor di air sumur gali desa Selabaya sebesar 0,3 mg/liter. Kadar sisa klor yang terendah yaitu $0,1 \mathrm{mg} / \mathrm{liter}$, sedangkan yang tertinggi sebesar 0,8 mg/liter. Pada tabel 4. 9 Hasil pengukuran pada hari pertama kadar sisa chlor pada SGL 1 yaitu didapatkan kadar sisa chlor dengan hasil $(0,1 \mathrm{mg} / \mathrm{l})$ yang tidak memenuhi standar dan SGL 6 yaitu didapatkan kadar sisa chlor dengan hasil $(0,8 \mathrm{mg} / \mathrm{l})$ tidak memenuhi standar di PERMENKES NO. 32 TAHUN 2017. Sedangkan SGL 2, SGL 3 SGL 4, SGL 5, SGL 7 dan SGL 8 yaitu sesuai dengan PERMENKES NO. 32 TAHUN 2017 (0,2 $\mathrm{mg} / \mathrm{l}-0,5 \mathrm{mg} / \mathrm{l})$.

5. Tabel 4.10 Pemeriksaan bakteri coliform di air sumur gali di Desa Selabaya Kecamatan Kalimanah Kabupaten Purbalingga

\begin{tabular}{|c|c|c|c|c|}
\hline No & Lokasi & $\begin{array}{l}\text { Standar } \\
\text { MPN / } \\
100 \mathrm{ml}\end{array}$ & $\begin{array}{c}\text { Hasil } \\
\text { pemeriksaan } \\
\text { sebelum } \\
\text { (11 April } \\
\text { 2018) } \\
\end{array}$ & $\begin{array}{c}\text { Hasil } \\
\text { pemeriksaan } \\
\text { sesuudah } \\
\text { (12 April } \\
\text { 2018) } \\
\end{array}$ \\
\hline 1 & SGL 1 & \multirow{8}{*}{50} & 1100 & 1100 \\
\hline 2 & SGL 2 & & 93 & 93 \\
\hline 3 & SGL 3 & & 460 & 23 \\
\hline 4 & SGL 4 & & 75 & 0 \\
\hline 5 & SGL 5 & & 460 & 460 \\
\hline 6 & SGL 6 & & 460 & 240 \\
\hline 7 & SGL 7 & & 150 & 0 \\
\hline 8 & SGL 8 & & 75 & 43 \\
\hline \multicolumn{2}{|c|}{ Standar } & kualitas & air bersi & sesuai \\
\hline \multicolumn{2}{|c|}{ ketentuan } & Peraturar & Menteri & esehatan \\
\hline \multicolumn{2}{|c|}{ Republik } & Indonesia & No.32 t & un 2017 \\
\hline & $\operatorname{lng}$ & andar $\mathrm{B}$ & ku Mutu & esehatan \\
\hline
\end{tabular}

Lingkungan Dan Persyaratan Kesehatan Air Untuk Keperluan Higiene Sanitasi, Kolam Renang, Solus Per Aqua, Dan Pemandian Umum yaitu untuk air bersih kadar maksimum yang diperbolehkan jumlah total Coliform dibawah $50 \mathrm{CFU} /$ $100 \mathrm{ml}$. Jika melebihi standar yang berlaku yaitu > $50 \mathrm{CFU}$ akan berisiko pencemaran air secara bakteriologis. Dari hasil uji laboratorium diketahui bahwa dari data sebelum dan sesudah ada yang mengalami perubahan dan ada yang tidak mengalami perubahan. Seperti sampel 1 tidak mengalami perubahan yaitu tetap 1100 MPN / 100 ml, sampel 2 juga tidak mengalami perubahan yaitu tetap 93 MPN / 100 ml, sampel 5 juga tidak mengalami perubahan yaitu tetap $460 \mathrm{MPN} / 100 \mathrm{ml}$. Dan pada sampel 6 terjadi penurunan dari 460 menjadi 240 MPN / $100 \mathrm{ml}$ tetapi masih di kelas kualitas air yang sama. Kemudian yang mengalami penurunan sampel 3, 4, 7, 8 mengalami penurunan menjadi lebih baik.

Hasil uji Laboratorium diketahui bahwa dari data sebelum dan sesudah ada yang mengalami perubahan dan tidak mengalami perubahan. Seperti sampel 1 tidak mengalami perubahan yaitu tetap 1100 MPN/100 ml, sampel 2 juga tidak mengalami perubahan yaitu tetap 93 MPN/100 ml, sampel 3 mengalami penurunan yang pada pemeriksaan awal 460 MPN/100ml setelah dipasang Chlorine Diffuser menjadi 23 MPN/100ml sudah sesuai dengan standar kualitas air bersih, sampel 4 mengalami penurunan menjadi lebih baik yang awalnya $75 \mathrm{MPN} / 100 \mathrm{ml}$ menjadi 0 MPN/100ml dan sudah sesuai dengan standar kualitas air bersih, sampel 5 juga tidak mengalami perubahan yaitu tetap 460 MPN / $100 \mathrm{ml}$. Sampel 6 terjadi penurunan dari $460 \mathrm{MPN} / 100 \mathrm{ml}$ menjadi 240 MPN / $100 \mathrm{ml}$ tetapi masih di kelas kualitas air yang sama. Pada sampel 7 mengalami penurunan menjadi lebih baik yang pemeriksaan awal 150 MPN / 100 ml menjadi 0 MPN / 100 ml. Kemudian pada sampel 8 pemeriksaan awalnya 75 MPN / $100 \mathrm{ml}$ menjadi $43 \mathrm{MPN} / 100 \mathrm{ml}$ 
dan sudah sesuai dengan standar kualitas air bersih. Sumur gali dengan Konstruksi sumur gali dapat berpengaruh terhadap kandungan bakteri coliform pada air sumur gali. Ada 8 sumur gali yang di teliti dan didapatkan 5 sumur gali tidak memenuhi syarat dan 3 sumur gali sudah memenuhi syarat. Sumur gali dengan volume air sumur gali juga berhubungan, karena saat volume air sumur gali itu lebih banyak maka habisnya kaporit dalam Chlorine diffuser juga semakin cepat. Chlorine diffuser dosisnya juga berpengaruh terhadap kualitas mikrobiologinya, Karena pada saat kita memakai perbandingan 1 : 4 itu paling lama bertahan selama 3 hari. Pada saat pengambilan sampel mikrobiologi peneliti bekerjasama dengan Laboratorium Kesehatatan Kabupaten Purbalingga, waktu yang diperlukan dari tempat pengambilan sampel ke Laboratorium adalah \pm 10 menit. Pada hari pertama peneliti menuju ke Laboratorium untuk meminjam alat dan bahan yang digunakan untuk pengambilan sampel Mikrobiologi, lalu peneliti mendatangi rumah ke 1 hingga ke 8 untuk pengambilan sampel air sumur galinya, setelah di ambil sampelnya lalu peneliti memasang Chlorine diffuser ke dalam sumur gali, setelah sumur gali 1 hingga 8 diambil sampel air sumur galinya selanjutnya sampel di antar ke Laboratorium untuk diperiksa. Peneliti tau jika pengambilan sampel Mikrobiologi yang benar seharusnya menggunakan botol timba yang steril tetapi ada kendala pada saat peminjaman alat di Laboratorium Purbalingga ternyata tidak menyediakan botol sampel yang ada timba pemberatnya, di Laboratorium hanya menyediakan botol steril saja karena kebanyakan sumur gali di Desa Selabaya menggunakan pompa air maka peneliti mengambil dari kran sesuai dengan cara pengambilan sampel air kran secara mikrobiologi yang peneliti liat dari "Buku Lembar Kerja Praktikum Mikrobiologi Lingkungan Poltekkes Kemenkes Semarang", tetapi ada kendala disaat 2 sumur yang tidak menggunakan pompa, maka peneliti harus mengambilnya dari sumurnya langsung. Dan yang peneliti lakukan adalah peneliti menggunakan timba kerekan lalu airnya dituang ke dalam botol sampel steril walaupun sudah dilengkapi dengan alkohol dan bunsen tetapi peneliti menyadari bahwa bisa saja terjadi kontaminasi. Setelah itu ditunggu hingga 1x24 jam, setelah didiamkan 1x24 jam pada jam yang sama di lakukan pengambilan sampel air sumur gali lagi yaitu sebagai sampel sesudah perlakuan/ sesudah pemasangan Chlorine diffuser lalu di antar menuju Laboratorium. Peneliti mengecek 2x karena peneliti ingin mengetahui hasil sebelum dan sesudah penggunaan Chlorine diffuser, apakah terjadi perubahan menjadi lebih baik atau tetap.

\section{Penutup}

1. Konstruksi sumur gali di Desa Selabaya Kecamatan Kalimanah Kabupaten Purbalingga ada 5 sumur gali yang masih belum memenuhi syarat dan 3 sumur gali sudah memenuhi syarat. Bibir sumur di sumur gali yang diteliti semuanya tingginya masih kurang dari $80 \mathrm{~cm}$.

2. Volume air sumur gali di Desa Selabaya Kecamatan Kalimanah Kabupaten Purbalingga mencukupi untuk keperluan sehari - hari.

3. Pembuatan chlorine diffuser menggunakan perbandingan $1: 4$ yaitu 1 $\mathrm{kg}$ kaporit dengan $4 \mathrm{~kg}$ pasir, didapatkan 12 chlorine diffuse.

4. Sisa chlor didapatkan Hasil pengukuran pada hari pertama kadar sisa chlor pada sampel sumur gali sampel 1 yaitu didapatkan kadar sisa chlor dengan hasil $(0,1 \mathrm{mg} / \mathrm{l})$ yang tidak sesuai dan sampel 6 yaitu didapatkan kadar sisa chlor dengan hasil $(0,8 \mathrm{mg} / \mathrm{l})$ tidak memenuhi standar di PERMENKES NO. 32 TAHUN 2017, sedangkan sampel sampel 2, sampel 3, sampel 4, sampel 5, sampel 7 dan sampel 8 yaitu sesuai dengan PERMENKES NO. 32 TAHUN 2017 (0,2 mg/l - 0,5 mg/l).

5. Kualitas mikrobiologi di Desa Selabaya Kecamatan Kalimanah Kabupaten 
Purbalingga didapatkan hasil setelah pemasangan chlorine diffuser kualitas airnya ada yang menjadi lebih baik dan ada yang tetap.

\section{Daftar Pustaka}

Air, rumah. "Parameter Air menurut Who dan Kemenkes RI". (http://rumahairbandung. Blogspot.co.id/2012/06/parameter-airmenurut-who-dan-kemenkes.html. Diakses 22 desember 2017)

Atiefsa, yelly. "Kesehatan Lingkungan". (http://yellyatiefsanarmala.blogspot.co.id/ 2012/12/ desinfeksi-air-dengan-chlorindiffuser.html.Diakses 14 desember 2017)

Cara menghitung volume galian. http://idebangunan.blogspot.co.id/2015/04 /cara-menghitung-volume-galiantanah.html. Diakses 8 Mei 2018 pukul 03.47 WIB.

Chandra. 2006. Pengantar Kesehatan Lingkungan, air permukaan merupakan salah satu sumber penting bahan baku air bersih.

Citra. 2017. Desinfeksi-air-dengan-chlorinediffuser. at http://blogspot.co.id, diakses 12_Desember 2017.

Departemen Kesehatan Republik Indonesia Direktorat Jenderal. 2007. "Pelatihan Penyehatan Air”. Jakarta. (hlm 45).

Dinas Kesehatan Kabupaten Purbalingga. 2016. "Profile Kesehatan Desa Selabaya Kecamatan Kalimanah Kabupaten Purbalingga 2016”

Fawanri Herwin Sinabang, 2009, Studi Kualitas Mikrobiologis Air Sumur Gali di Kelurahan Larangan Kecamtan Larangan Kabupaten Brebes Tahun 2009, KTI, Purwokerto: Jurusan Kesehatan Lingkungan Purwokerto
Hastari Wuryastuti. 2000. Jurnal Sain Veteriner Faculty Of Veterinary Medicine. Universitas Gadjah Mada. Yogyakarta. (https://jurnal.ugm.ac.id/jsv/article/view/2 60) di akses pada tanggal 30 April 2018 pukul 07.52 WIB.

Herlambang, Arie dkk. 2010. Menteri Pelatihan Teknologi Pengolahan Air Bersih. Jakarta: Pusat Teknologi Lingkungan Deputi Bidang Teknologi Pengembangan Sumber Daya Alam Badan Pengkajian dan Penerapan Teknologi.

Kementrian Kesehatan Republik Indonesia. 2001. Peraturan Pemerintah Republik Indonesia Nomer 82 Tahun 2001 Tentang Pengelolaan Kualitas Air dan Pengendalian Pencemaran Air.

Kementrian Kesehatan Republik Indonesia. 2014. Peraturan Pemerintah Republik Indonesia Nomor 66 Tahun 2014 Tentang Kesehatan Lingkungan, kualitas lingkungan yang sehat.

Kementrian Kesehatan Republik Indonesia. 2017. Peraturan Menteri Kesehatan Republik Indonesia Nomer 32 tahun 2017 Tentang Standar Baku Mutu Kesehatan Lingkungan dan Persyaratan Kesehatan Air untuk Keperluan Higiene Sanitasi, Kolam Renang, Solus Per Aqua, dan Pemandian Umum.

Lembar kerja praktikum mikrobioologi lingkungan

Oksandi Hardiansyah. 2014. Uji kualitas air menggunakan metode MPN. (http://bloomadailmu.blogspot.co.id/2014/ 04/uji-kualitas-air-menggunakan-metodempn.html). di akses pada tanggal 30 April 2018 pukul 08.02 WIB.

Pedoman Teknis Perbaikan Kualitas Air Pembuatan Sumur Gali Ditjen P2M dan PLP 1996 (hlm. 2) 
Poliklinik Desa Selabaya Kecamatan Kalimanah Kabupaten Purbalingga. 2017. "Laporan Bulanan $10 \quad$ Besar Penyakit PUSTU/PKD”

Sanropie, Djasio. 1984. "Standar Kualitas Air". (hlm. 52)

Standar operasional prosedur. UPTD laboratorium kesehatan kabupaten purbalingga : Pemeriksaan Coliform
Undang Undang Dasar Negara Republik Indonesia Tahun 1945. Pasal 33 ayat (3) yang bunyinya sebagai berikut: Bumi, air dan kekayaan alam yang terkandung didalamnya dikuasai oleh Negara dan dipergunakan untuk sebesar-besarnya kemakmuran rakyat.

Undang - Undang Republik Indonesia Nomor. 7 Tahun 2007. "Tentang Sumber Daya Air”. 